\title{
Psychometric properties of a scale to measure the dark side of personality
}

\author{
Propriedades psicométricas de uma escala para \\ medir o lado escuro da personalidade
}

\author{
Solana SALESSI ${ }^{1,2}$ iD 0000-0001-9496-9493 \\ Alicia OMAR ${ }^{1}$ (iD) 0000-0001-6613-2565
}

\begin{abstract}
The psychometric characteristics of the Dark Triad Scale in an Argentinian context are presented. Two successive studies were carried out. Three hundred sixteen people, with an average age of 34.48 years $(S D=10.57)$, participated in Study 1. An exploratory factor analysis indicated a three-factor structure with suitable internal consistency (Machiavellianism: $a=0.92$; narcissism: $\alpha=0.91$, and psychopathy: $\alpha=0.89$ ). Two hundred seventy-five people, with an average age of 32 years $(S D=8.10)$, participated in Study 2. A confirmatory factor analysis corroborated the three-factor structure. The three factors reached Satisfactory Composite Reliability (greater than 0.70) and adequate Convergent-Discriminant Validity (Average Variance Extrated greater than 0.50). The invariance of the scale's parameters was demonstrated by sex. The results indicate that the Argentinian version of the Dark Triad Scale measures the dark side of personality with appropriate validity and reliability, both in men and women.
\end{abstract}

Keywords: Antisocial personality disorder; Machiavellianism; Narcissism; Psychometrics; Statistical validity.

\section{Resumo}

Este estudo apresenta as características psicométricas da Dark Triad Scale para o contexto da Argentina. Dois estudos sucessivos foram realizados. Participaram do primeiro estudo trezentas e dezesseis pessoas, com uma idade média de 34,48 anos $(D P=10,57)$. A análise fatorial exploratória indicou uma estrutura de três fatores com adequada consistência interna (Maquiavelismo: $\alpha=0,92$; narcisismo: $\alpha=0,91$, e psicopatia: $\alpha=0,89$ ). Do segundo estudo participaram duzentas e setenta e cinco pessoas, com uma idade média de 32 anos $(D P=8,10)$. A análise fatorial confirmatória confirmou a adequação da estrutura trifatorial. Os três fatores resultantes apresentaram Confiabilidade Composta Satisfatória (maior que 0,70 ) e indicadores adequados de validade convergente-discriminante (AVE maior que 0,50). A invariância dos parâmetros da escala foi demonstrada por meio do sexo. Os resultados indicam que a versão argentina da Dark Triad Scale mede o lado escuro da personalidade com validade e confiabilidade adequadas, tanto em homens quanto em mulheres.

Palavras-chave: Transtorno da personalidade antissocial; Maquiavelismo; Narcisismo; Psicometria; Validade fatorial.

$\checkmark v \nabla v$

1 Ministério de Ciencia, Tecnología e Innovación Productiva de Argentina, Consejo Nacional de Investigaciones Científicas y Técnicas, Instituto de Investigaciones de la Facultad de Humanidades y Artes de la Universidad Nacional de Rosario, Argentina.

2 Pontificia Universidad Católica Argentina, Facultad de Derecho y Ciencias Sociales de Rosario. Av. Pellegrini 3314 (2000) Rosario, Argentina. Correspondência para/Correspondence to: S. SALESSI. E-mail: <solanasalessi@gmail.com>.

$\boldsymbol{\nabla} \mathbf{v} \boldsymbol{v}$

Como citar este artigo/How to cite this article

Salessi, S., \& Omar, A. (2018). Psychometric properties of a scale to measure the dark side of personality. Estudos de Psicologia (Campinas), 35(2), 159-170. http://dx.doi.org/10.1590/1982-02752018000200005 
The study of the darkest and most shadowed characteristics of personality has a long history in the field of psychology. Recent years have witnessed a renewed interest that has repositioned the subject in a prominent place on the scientific agenda. The epithet "dark personality" refers to an eclectic group of characteristics between "normal" (luminous) and "anomalous" traits. The latter are located below the clinical threshold and do not imply a psychopathological alteration (Spain, Harms, \& Lebreton, 2013). That is, the dark characteristics of personality do not necessarily imply obstacles or difficulties and may even be associated with certain positive attitudes, as evidenced by the recent study by Palaiou, Zarola, and Furnham (2016). However, under adverse conditions, they can harm the quality of interpersonal relationships, health and individual well-being (Furnham, Richards, \& Paulhus, 2013; Hudek-Knežević, Kardum, \& Mehić, 2016; Ronchetti et al., 2014).

Although there is no consensus on how many features are integrated in the dark side of personality, the current trend considers Machiavellianism, narcissism and psychopathy to be the most prominent ones (Marcus \& Zeigler-Hill, 2016).

Machiavellianism is characterized by cunning, cynicism, selfishness and the strategic manipulation of others. The distinguishing marks of narcissism are grandiosity, individualism and an unrealistic self-image. Meanwhile, insensitivity, contempt for others, tendency towards provocation, deception, loquacity and superficial charm are characteristics of psychopathy. Despite the peculiarities inherent in each of these traits, the empirical evidence (Jones \& Figueredo, 2013; Southard, Noser, Pollock, Mercer, \& Zeigler-Hill, 2015; Stead \& Fekken, 2014) suggests that they share common elements such as emotional coldness, lack of empathy, dishonesty, arrogance, manipulation, and egocentrism, which, as a whole, is identified as the "Dark Triad" (Paulhus, 2014).

Initially, the study of the Dark Triad was performed with instruments designed to explore each of its components individually. Therefore, for example, the measurement of narcissism was carried out with the Narcissistic Personality Inventory (Raskin \& Hall, 1979); the Mach-IV Scale was used to explore Machiavellianism (Christie \& Geis, 1970), while the Self-Informed Scale of Psychopathy (Hare, 1985) was the most commonly used instrument to evaluate this trait. The common denominator of these instruments is their considerable length (between 40 and 64 items), which generates practical difficulties at the time of their application.

With such drawbacks, there are now some measures available that allow us to evaluate the three components of the triad through a single instrument. Jones and Paulhus' Dark Triad Scale (2014) is one of the best examples. It is a scale developed and subjected to extensive validation studies with samples of slightly more than 1000 North American and Canadian adults. The final version is composed of 27 items that measure the dimensions of Machiavellianism ( $a=0.77$ ), narcissism ( $\alpha=0.71)$ and psychopathy $(\alpha=0.80)$, with a ratio of 9 items each. As it is a relatively new instrument, a few adaptation studies have been reported in other cultural contexts. However, the few published validation works (Maples, Lamkin, \& Miller, 2014) confirm the adequate psychometric properties of the scale.

Until now, there is no standardized version for the Spanish-speaking population in general, or for Argentina in particular. Therefore, to cover this empirical-instrumental gap, the objective of the present study was to adapt and validate Jones and Paulhus' Dark Triad Scale for use in Argentinian populations.

\section{Method}

\section{Design}

The present work is included in the category of instrumental investigations (Ato, López, \& Benavente, 2013) because it was oriented to the adaptation and validation of a measurement instrument. The work is structured based on two complementary studies, labelled Study 1 and Study 2, respectively. The execution of both studies was carried out in accordance with the ethical guidelines established by the American 
Psychological Association and the Consejo Nacional de Investigaciones Científicas y Técnicas (CONICET, National Board of Scientific and Technical Investigation) recommendations for research in the social and human sciences (Resolution 2827/06).

\section{Study 1}

The objective of this first study was to translate, adapt and explore the factorial structure of the Dark Triad Scale (Jones \& Paulhus, 2014) in the Argentinian population. Previously, and in line with the most up-to-date suggestions (Muñiz, Elosua, \& Hambleton, 2013), the degree of conceptual, semantic, operational and metric equivalence between the adapted version and the original version of the instrument was determined.

Conceptual equivalence refers to the search for correspondences of the concepts to be measured between the culture where the instrument was developed and the target culture in which it will be applied. For this purpose, a bibliographical review was carried out on the Machiavellian, narcissism and psychopathy constructs in the original culture of the scale United States of America (USA) and in Argentina. Simultaneously, the items were exposed to critical review by two specialized professionals, one in Clinical Psychology and another one in Personality Psychology. The specialists received a booklet containing conceptual and operational definitions of the constructs, as well as all the items that integrated the scale. The guiding instruction was that considering their expert judgement, they would classify each item in the corresponding dimension. They were also encouraged to make comments and suggestions to improve the prototypical version of the instrument.

Semantic equivalence consists of the translation of the items, preserving the meaning among the languages involved. This analysis was carried out in three stages and with the participation of two professional translators. First, the original instrument was translated from English into Spanish (Argentinian). Subsequently, the English-language experts retranslated the Argentinian version into the original language. Finally, the same translators blindly compared the two versions of the instrument to identify the agreement between each item and its translation according to four levels of equivalence: unaltered, slightly altered, quite altered and completely altered.

Operational equivalence refers to the maintenance of the operational characteristics regarding the clarity of the instructions, the semantic and syntactic adequacy of the items and the time required to complete the task. For the analysis of this equivalence, a pilot study was carried out on an available sample of 26 postgraduate students (58\% women, 31 years of age on average) who voluntarily agreed to respond the protocol. Once the application of the scale was completed, an interchange room was enabled so that the participants could comment on the clarity of the items, possible ambiguities, the time required to answer them and similar aspects.

Finally, for metric equivalence analysis, a new sample was studied considering availability, following the procedure and data analysis strategy described below.

\section{Participant}

The work was based on an availability sample of 316 young and middle-aged people who live in the Argentine city of Rosario. Approximately 52\% of the participants were women. The average age was 34.48 years old $(S D=10.57)$. Approximately $42 \%$ of the participants were married or in a relationship, and $64 \%$ had completed tertiary or university studies. Lastly, $53 \%$ of the participants were employees and $28 \%$ were independent professionals.

\section{Procedure}

The data were collected during the first half of 2015. Participants were informed of the research objectives and were guaranteed anonymity and confidentiality regarding the information they provided. The administration oversaw the trained staff for this purpose. 


\section{Instrument}

The translated Spanish version of the Dark Triad scale was used (Jones \& Paulhus, 2014). It was integrated by the 27 original items, presented randomly in a 5-point Likert format ( 1 = Totally disagree; $5=$ Totally agree). Examples of the items are as follows: "Most people can be manipulated" (Machiavellianism); "I demand that I am treated with the respect I deserve" (narcissism), and "I could say anything to get what I want" (psychopathy).

\section{Data analysis strategy}

First, the descriptive statistics (means and standard deviations), the asymmetry and kurtosis indexes and the discrimination indexes (considering the calculation of item-corrected total correlations) were obtained for each of the items. Next, the sample adequacy indexes were obtained (KaiserMeyer-Olkin tests and Bartlett's sphericity).

The underlying structure of the items was determined using an Análisis Factorial Exploratorio (AFE, Exploratory Factor Analysis). Due to the ordinal nature of the data, the Unweighted Least Squares (ULS) method was used based on an array of polychromatic correlations (Lloret-Segura, Ferreres, Hernández, \& Tomás, 2014). To determine the number of factors, a two-step analytical strategy was applied (Baglin, 2014). That is, an optimized parallel analysis was first executed, randomly extracting 500 sub-matrixes and implementing the minimum range analysis; then, the extraction of the suggested factors was carried out, opting for the Promin oblique rotation since there was the presumption that the elements of the scale were related. Complementarily, the scree test was evaluated (considering the components located above the curve of the sedimentation graph). The criterion for selecting the items was that they weighed 0.40 or more over the factor and that they did not saturate significantly over more than one factor at the same time (Lloret-Segura et al., 2014). The preliminary reliability of the instrument was assessed using the alpha ordinal statistic, variables (Gadermann, Guhn, \& Zumbo, 2012). Data processing and analysis were performed with Statistical Package for Social Sciences (SPSS IBM, Armonk, NY, United States) software version 19.0 and Factor version 9.2 (Departament de Psicologia Universitat Rovira i Virgili, Tarragona, Spain).

\section{Results}

\section{Conceptual, semantic and operational equivalence}

The analysis of the specialized literature (Marcus \& Zeigler-Hill, 2016) indicated that the Machiavellianism, narcissism and psychopathy constructs are equivalent in both cultures (North American and Argentinian cultures). The review of the content of each item performed by the two professionals, considering their experience and the scientific bibliography on the subject, indicated that the items included in the scale covered the domains postulated by Jones and Paulhus (2014). It was found that the terminology used in the items reflected the typical vocabulary of the Argentinian population, so no additional modifications were necessary. Regarding linguistic adaptation, both professionals indicated that concordance between each original item and that translated into Spanish had been unaltered. Therefore, they concluded that the Argentinian version of the Dark Triad Scale had an adequate semantic equivalence. Regarding the operational equivalence, the participants of the pilot study indicated that the instructions to perform the task were clearly written, that they did not have problems in understanding the content of the items, and the Likert scale used to answer the items did not create any difficulties.

\section{Preliminary analysis}

Table 1 presents the descriptive statistics, asymmetry and kurtosis indexes and discrimination indexes for each item. Of the 27 items, 24 presented values of asymmetry and kurtosis between -1 and +1 . Three items corresponding to the psychopathy 
Table 1

Descriptive statistics, asymmetry and kurtosis indexes, and corrected item-total correlation corresponding to the items of the Dark Triad Scale (adapted version)

\begin{tabular}{|c|c|c|c|c|c|c|}
\hline Subscale & Item & Average & $S D$ & Asymmetry & Kurtosis & $r$ i-total \\
\hline \multirow{9}{*}{ Machiavellianism } & 1 & 3.53 & 1.17 & 0.42 & -0.63 & 0.79 \\
\hline & 2 & 3.48 & 1.14 & 0.44 & -0.50 & 0.77 \\
\hline & 3 & 3.21 & 1.23 & 0.47 & 0.70 & 0.82 \\
\hline & 4 & 3.43 & 1.09 & -0.45 & -0.54 & 0.77 \\
\hline & 5 & 3.19 & 1.04 & -0.48 & 0.88 & 0.89 \\
\hline & 6 & 3.26 & 1.06 & 0.39 & -0.91 & 0.88 \\
\hline & 7 & 3.32 & 1.07 & -0.35 & 0.90 & 0.82 \\
\hline & 8 & 3.36 & 1.27 & -0.31 & -0.61 & 0.77 \\
\hline & 9 & 3.30 & 1.14 & 0.54 & 0.50 & 0.58 \\
\hline \multirow{9}{*}{ Narcissism } & 10 & 3.21 & 1.02 & -0.24 & -0.53 & 0.74 \\
\hline & 11 & 3.56 & 1.15 & 0.52 & -0.28 & 0.80 \\
\hline & 12 & 3.36 & 1.22 & 0.60 & 1.18 & 0.71 \\
\hline & 13 & 3.12 & 1.10 & 0.30 & 1.03 & 0.70 \\
\hline & 14 & 3.19 & 1.15 & -0.37 & -0.23 & 0.73 \\
\hline & 15 & 3.08 & 1.05 & -0.42 & 0.37 & 0.77 \\
\hline & 16 & 3.26 & 1.25 & 0.47 & 0.28 & 0.79 \\
\hline & 17 & 3.38 & 1.26 & -0.62 & -0.22 & 0.80 \\
\hline & 18 & 3.62 & 1.17 & -0.56 & -0.26 & 0.71 \\
\hline \multirow{9}{*}{ Psychopathy } & 19 & 2.91 & 0.98 & 1.31 & -1.56 & 0.48 \\
\hline & 20 & 3.59 & 1.11 & -0.12 & 0.42 & 0.74 \\
\hline & 21 & 3.27 & 1.08 & 0.39 & 0.63 & 0.71 \\
\hline & 22 & 2.56 & 1.12 & -1.46 & -1.23 & 0.46 \\
\hline & 23 & 3.23 & 1.02 & -0.68 & 0.37 & 0.74 \\
\hline & 24 & 3.19 & 1.23 & 1.11 & 0.28 & 0.73 \\
\hline & 25 & 3.48 & 1.06 & -0.87 & -0.22 & 0.66 \\
\hline & 26 & 2.62 & 1.26 & -1.49 & -1.27 & 0.45 \\
\hline & 27 & 3.37 & 1.19 & -0.43 & 0.32 & 0.62 \\
\hline
\end{tabular}

Note: SD: Standard Deviation.

sub-scale presented higher indexes. However, because they reached scores lower than 1.60, they were assessed as acceptable (Hair, Black, Babin, Anderson, \& Tatham, 2010). In terms of discriminative capacity, all the items showed positive correlations.

\section{Exploratory factor analysis}

The data matrix was considered factorizable because the Bartlett sphericity test was significant $\left(\chi^{2}(316)=2886.252, g L=351, p<0.001\right)$ and the Kaiser-Meyer-Olkin sample adequacy index produced a value of 0.91 . The optimized parallel analysis suggested three factors with eigenvalues greater than their equivalent of the random data matrix. The scree test for the magnitude of eigenvalues also indicated the relevance of retaining three factors (Figure 1).

Three items whose saturations did not reach the established threshold were eliminated (item 19: "I like to take revenge on those who have more power than me", item 22: "I like to have sex with people I barely know", and item 26: "People usually tell me that I am a runaway"). Therefore, 24 out of the 27 reagents of the original scale were retained. The calculation of a second AFE, extracting the three factors suggested initially and applying the Promin rotation, confirmed this solution. The overall percentage of common variance explained by the 


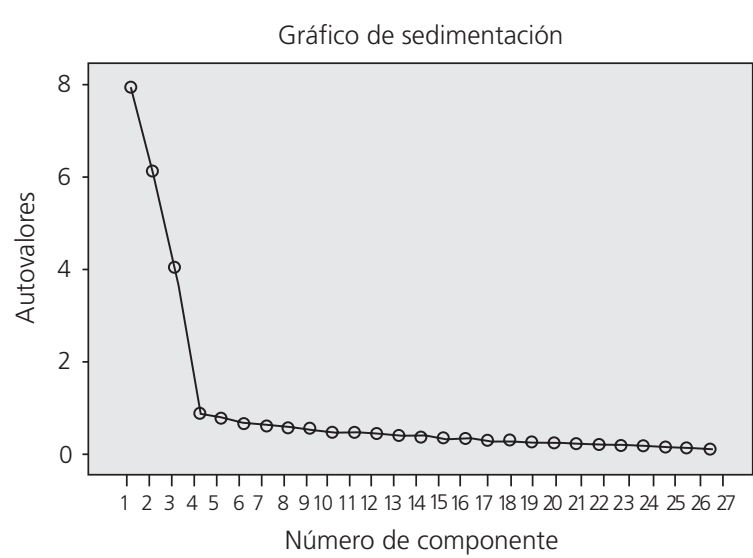

Figure 1. Scree plot corresponding to the AFE of the Dark Triad Scale adaptation

three extracted factors was $65.44 \%$. The distribution of the reactants coincided with the three dimensions originally proposed by Jones and Paulhus (2014), which were labelled Machiavellianism (Factor 1), Narcissism (Factor 2) and Psychopathy (Factor 3), respectively. Considering the recommendations of the specialized literature (Lloret-Segura et al., 2014), Table 2 reports not only the configuration matrix with the factorial saturations of each item in each factor but also the structure matrix containing the correlations between observable variables and latent variables.

\section{Reliability analysis}

The analysis of the preliminary reliability indicated optimal levels of consistency and homogeneity. The alpha ordinal coefficients for each of the three dimensions were very significant (Machiavellianism: $a=0.92$, narcissism: $\alpha=0.91$, and psychopathy: $\alpha=0.89$ ). The total scale reached a value of 0.90 .

\section{Study 2}

The objective of this study was to confirm the factor structure of the Dark Triad Scale identified in Study 1 and to analyse the psychometric properties of the instrument. Considering the data obtained in a new sample of the target population, a Analisis

164 Factorial Confirmatorio (AFC, Factorial Confirmatory
Analysis) was carried out based on the strategy of rival models. Measurements of composite reliability and discriminant and convergent validity were obtained. Likewise, the assumptions of configural and metric invariance between men and women were contrasted. The configural invariance refers to the equivalence of the factorial structure between the different groups. The metric invariance concerns the degree to which the parameters of the model (in this case the factor loads) are similar between the groups compared.

\section{Participants}

The sample size was determined based on the criterion of having a minimum of 200 cases to ensure that the factor solution was stable and generalizable (Lloret-Segura et al., 2014). An initial sample of 287 participants was incorporated, of which twelve cases were discarded for not having fully completed the data collection protocol. The final sample consisted of 275 young people and adults (147 males and 128 females). The average age of the women $(S D=7.42)$ was 31 years, while that of the men was 34 years $(S D=9.21)$. Approximately $45 \%$ of the sample had higher education (tertiary and/or university) and 53\% worked in the private sector.

\section{Procedure}

The data were collected during the second half of 2015. The only participants selected were those who, after knowing the objectives of the research, gave their voluntary written consent. There were no incentives of any type. The anonymity and confidentiality of the information were guaranteed, as well as the possibility of withdrawing their participation. In all cases, the administration oversaw the trained staff.

\section{Instrument}

The dark triad was measured with the selfadministered version (translated into Spanish and developed during Study 1) of Jones and Paulhus' 
Table 2

Configuration matrix and Structural matrix corresponding to the items of the Dark Triad Scale (adapted version)

1 of 2

\begin{tabular}{|c|c|c|c|c|c|c|}
\hline \multirow{2}{*}{$\begin{array}{l}\text { Contents of the Item } \\
\text { Machiavellianism }\end{array}$} & \multicolumn{3}{|c|}{ Configuration Matrix } & \multicolumn{3}{|c|}{ Structural Matrix } \\
\hline & I & $\|$ & III & I & $\|$ & III \\
\hline 1. No es conveniente contar nuestros secretos & 0.85 & & & 0.68 & & \\
\hline
\end{tabular}

[It is not advantageous to disclose our own secrets]

2. Las personas no se esfuerzan demasiado a no ser que tengan que hacerlo $\quad 0.81 \quad 0.65$

[People do not work harder unless they have to]

3. Hay que hacer cualquier cosa con tal de conseguir el apoyo de las $0.84 \quad 0.70$

personas poderosas

[You have to do anything to get the support of powerful people]

4. Hay que evitar tener conflictos con los demás, ya que nos pueden ser 0.80 útiles en el futuro

[You have to avoid conflicts with other people, as they may be helpful in the future]

5. Es bueno guardar información que después se pueda usar en contra de los otros

[It is good to keep information that later can be used against others]

6. Hay que saber esperar el momento adecuado para vengarse [You have to wait for the right time to get revenge]

7. Hay que asegurarse que nuestros planes nos beneficien sólo a nosotros, no a los demás [We must make sure that our plans benefit us only, and not other people]

8. Hay cosas que deben ocultarse, ya que los demás no necesitan saberlo [There are things that must be hidden since others do not need to know]

9. La mayoría de las personas pueden ser manipuladas

[Most people can be manipulated]

Percentage of variance explained: $28.91 \%$

Narcissism

10. La gente me ve como a un líder natural

[People see me as a natural leader]

11. No me gusta ser el centro de atención $\left({ }^{*}\right)$

[I do not like being the centre of attention]

12. Si yo no estoy, las reuniones suelen ser aburridas

13. Yo sé que soy especial porque todo el mundo me lo dice

[I know I am special because everybody tells me so]

14. Me gusta "codearme" con gente importante

[I like to get acquainted with important people]

15. Me siento avergonzado si alguien me elogia $\left(^{*}\right)$

[I feel ashamed if someone praises me]

16. Soy una persona común $\left({ }^{*}\right)$

[I am an ordinary person]

17. He sido comparado con gente famosa

[I have been compared to famous people]

18. Exijo que me traten con el respeto que merezco

[I demand that people treat me with the respect I deserve]

Percentage of variance explained: $22.59 \%$

\section{Psychopathy}

19. Evito las situaciones peligrosas $\left({ }^{*}\right)$ 
Table 2

Configuration matrix and Structural matrix corresponding to the items of the Dark Triad Scale (adapted version)

\begin{tabular}{|c|c|c|c|c|c|c|}
\hline \multirow{2}{*}{$\begin{array}{l}\text { Contents of the Item } \\
\text { Psychopaty }\end{array}$} & \multicolumn{3}{|c|}{ Configuration Matrix } & \multicolumn{3}{|c|}{ Structural Matrix } \\
\hline & । & $\|$ & III & I & $\|$ & III \\
\hline $\begin{array}{l}\text { 20. La venganza debe ser rápida y contundente } \\
\text { [Revenge must be quick and forceful] }\end{array}$ & & & 0.68 & & & 0.67 \\
\hline $\begin{array}{l}\text { 21. Los que se meten conmigo terminan lamentándolo } \\
\text { [People who mess with me end up regretting it] }\end{array}$ & & & 0.80 & & & 0.80 \\
\hline $\begin{array}{l}\text { 22. Nunca he tenido problemas con la ley }\left(^{*}\right) \\
\text { [I have never had problems with the law] }\end{array}$ & & & 0.76 & & & 0.62 \\
\hline $\begin{array}{l}\text { 23. Me gusta burlarme de los perdedores } \\
\text { [I like to make fun of losers] }\end{array}$ & & & 0.79 & & & 0.73 \\
\hline $\begin{array}{l}\text { 24. Podría decir cualquier cosa con tal de conseguir lo que quiero } \\
\text { [I could say anything to get what I want] } \\
\text { Percentage of variance explained: } 13.94 \%\end{array}$ & & & 0.68 & & & 0.71 \\
\hline
\end{tabular}

Note: the asterisk indicates the reverse items.

homonymous scale (2014), integrated by 24 items with a Likert 5-point format (ranging from $1=$ Strongly disagree 5 = Strongly agree).

\section{Data analysis strategy}

The data matrix was examined, expecting to detect the presence of missing values and univariate and/or multivariate atypical scores (Hair et al., 2010). The multi-normality assumption was verified by means of the calculation of normalized Mardia Coefficient (Bentler, 2006). The adjustment of the tri-factorial, non-hierarchical and oblique model obtained in the AFE was compared with two other alternative models: a uni-factorial model in which all the items saturated into a single latent factor and a hierarchical model in which a second-order factor representative of a general dark triad construct was included. In the execution of AFC, the maximum likelihood estimation method Maximum Likelihood $(\mathrm{ML})$ was used with the robust correction of SatorraBentler (Bentler, 2006, Satorra, 2002). To evaluate the goodness of adjustment of each model, the $\mathrm{S}-\mathrm{B} \chi^{2}$ correction on degrees of freedom (S-B $\chi^{2} / \mathrm{gL}$ ) was analysed to be less than 3 ; it was also analysed that the Goodness of Fit Index (GFI) and the
Comparative Fit Index (CFI) may reach values equal to or greater than 0.90 and that the Root Mean Square Error of Approximation (RMSEA) would be less than 0.05. In addition, the Akaike Information Criterion (AIC) was examined; the lower its value, the more parsimonious the model. Reliability was determined with the Composite Reliability (CR). The convergent validity was verified by means of the calculation of the Average Variance Extracted (AVE), while the discriminant validity was obtained from the square root of the AVE. To explore the configural invariance, a multi-group AFC was performed, adjusting the model without restrictions in males and females. To determine the metric invariance, the $\chi^{2}$ difference test was performed, contrasting the $\chi^{2}$ obtained in a non-constrained model with the $\chi^{2}$ corresponding to a model with restrictions on the regression coefficients. If this value is statistically significant, it indicates that the restrictions specified in the most restrictive model are not supported; this is to say, the two models are not equivalent between the groups (Hair et al., 2010). Data processing and analysis was performed with Statistical Package for Social Sciences (SPSS) software version 19.1 (IBM, Armonk, NY, United States) and EQS version 6.1 (Multivariate Software, Encino, CA, United States). 


\section{Results}

\section{Preliminary Analyses}

The initial exploration showed no missing values. However, four marginal scores out of the $+/-3$ range were recorded, and three values exceeded the established threshold of 0.001 in the D 2 statistic of the Mahalanobis distance. In line with these findings, the value of the standard Mardia coefficient slightly exceeded the acceptable limit, showing a value of 4.87 . In view of these results, robust estimators were considered for the execution of the AFC. The results for each of the contrasted models are presented below.

\section{Confirmatory Factor Analysis}

"Oblique tri-factorial model (three latent factors correlated with 24 items as observable indicators and their respective measurement errors)": the results showed that this model presented a satisfactory adjustment to the empirical data $\left(S-B \chi^{2} / g L=1.21 ; G F I=0.90 ; C F I=0.97\right.$; RMSEA $=0.03, / C 90 \%$ [0.02; 0.04]; $\mathrm{AIC}=506.298)$. Standardized factor loads were found to be between 0.78 and $0.92(p<0.001)$ for the Machiavellian factor; between 0.68 and $0.83(p<0.001)$ for the narcissism factor; and between 0.73 and $0.79(p<0.001)$ for the psychopathy factor. The covariates were in the order of 0.38 for the factors Machiavellianism and psychopathy; in the order of 0.25 for narcissism and Machiavellianism, and; in the order of 0.31 for narcissism and psychopathy.

"Hierarchical model (a second-order factor and three first-order factors with 24 items as observable indicators and their respective measurement errors)": The adjustment indicators obtained for this model were not adequate $\left(S-B \chi^{2} / g L=1.37\right.$; $G F I=0.82 ; C F I=0.86 ; R M S E A=0.06, / C 90 \%$ [0.05; 0.07]; $A / C=552.677)$. In addition, the calculation of the omega coefficient (Zinbarg, Yovel, Revelle, \& McDonald, 2006) did not reach the established minimum of $0.50(\omega h=0.24)$. This result indicated that the proportion of variance in the scale scores was not explained by a general factor, so there was no evidence to support that the dimensions of Machiavellianism, narcissism, and psychopathy were embedded in a second-order factor.

"Unifactorial model (a latent factor with 24 items as observable indicators with their respective measurement errors)": The results indicated that this model had an inadequate adjustment $\left(S-B \chi^{2} / g L=6.68 ; G F I=0.30 ; C F I=0.32\right.$; RMSEA $=0.19$, IC $90 \%[0.18 ; 0.20] ; A / C=2288.395)$. The standardized factor loads were found to be between 0.10 and $0.80(p<0.05)$. The elimination of the model of the three items with lower factorial loads (item) did not cause any improvement on the degree of adjustment $\left(S-B \chi^{2} / g L=5.68 ; G F I=0.34\right.$; $C F I=0.36 ;$ RMSEA $=0.14$, IC 90\% [0.13; 0.15]; $A / C=2138.021)$.

The results obtained confirmed that the non-hierarchical three-factor oblique model is the most parsimonious and the most adjusted model to the empirical data matrix. Figure 2 shows the final structure of the scale and the standardized coefficients corresponding to each of the items.

\section{Reliability and convergent and discriminant validity analysis}

The calculation of the composite reliability coefficient extensively exceeded the minimum established by the literature: 0.95 for the Machiavellian subscale, 0.92 for narcissism, and 0.91 for psychopathy. The AVE coefficient was above 0.50 , reaching values of $0.70,0.58$ and 0.53 , respectively. The square root of the AVE was greater than the correlation between the constructs in all cases. Specifically, a value of 0.84 was obtained for Machiavellianism, 0.76 for narcissism, and 0.72 for psychopathy.

\section{Analysis of invariance by sex}

The multi-group AFC by gender determined that the factor structure was adequate when both groups were tested together with no restrictions 


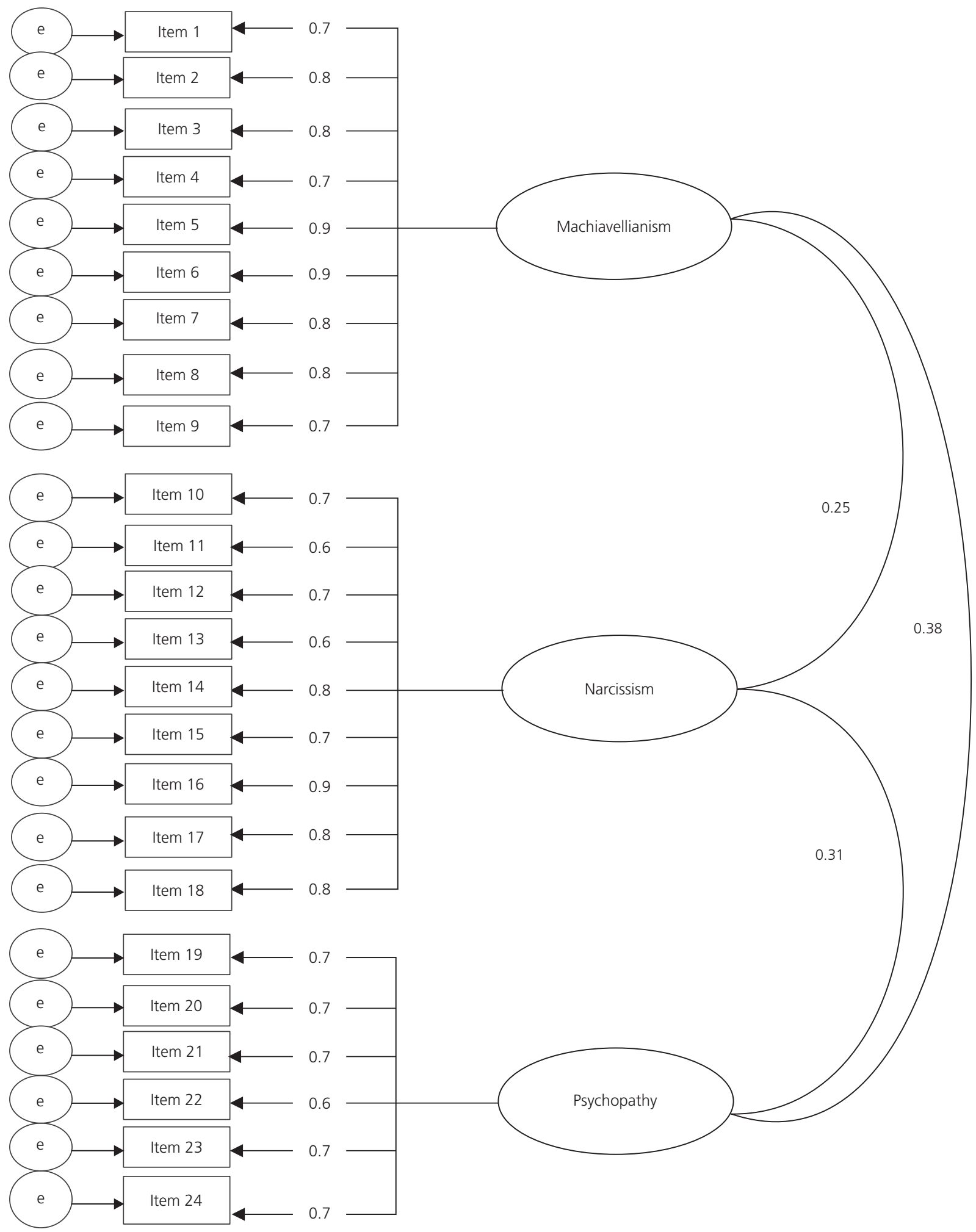

Figure 2. Factor structure corresponding to the adapted version of the Dark Triad Scale.

$\left(S-B \chi^{2} / g L=1.38, G F I=0.90, C F I=0.91, R M S E A=0.03\right.$ IC 90\% [0.02; 0.04]). Regarding measurement

168 invariance, the $\chi^{2}$ difference test did not reach statistically significant values $\left(D \chi^{2}=27.9, g L=27, p=0.416\right)$. This indicated that there were no differences based on the sex of the respondents. 
General discussion

The aim of the present study was to adapt and validate Jones and Paulhus' Dark Triad Scale (2014) for use in Argentinian populations. Study 1 and Study 2 showed that the scale has a trifactorial structure, a consistent conclusion both with the theoretical foundations and the factorial composition of the original scale (Jones \& Paulhus, 2014), as well as with the results reported by Maples et al. (2014).

The results also indicated that the scale has an appropriate convergent-discriminant validity, which means that the variance captured by the identified factors (Machiavellianism, narcissism and psychopathy) is greater than that explained by the measurement errors and can be adequately explained through the chosen indicators. Likewise, the results showed that the Argentinian version of the scale has an acceptable internal consistency comparable to that of the original version. The AVE values showed that the three sub-scales share more than $50 \%$ of their variance with their respective indicators. All the constructs presented adequate discriminant validity since the square root of the AVE is greater than the squared correlation between each dimension and the others. Likewise, the results indicate the invariance of the instrument both at the configural and at the metric level, which is the reason why the scale can be used with the same validity and reliability with samples of men and with samples of women.

Among the main limitations of the present research, it is necessary to mention the representativeness of the sample, as having worked with samples considering availability would make it difficult to generalize the results to the population as a whole. Another limitation would be related to the external validity of the validated instrument. In this regard, as the stability of dimensions over time has not been verified. It would be advisable to explore the test-retest reliability of the scale in future studies. Finally, as the scale evaluates the self-perceived dark traits, responses could be contaminated by both social desirability and other subjective components.
Despite the listed limitations, having a scale with adequate psychometric properties to measure the darker side of personality has many practical benefits, not only at the clinical level but especially at the organizational level. In this respect, given the contribution that the negative personality characteristics have on the emergence and development of some organizationally harmful behaviours (Linstead, Maréchal, \& Griffin, 2014), the measurement of the dark triad can help both staff selectors and specialists in developing organizational strengths. For example, the professionals in charge of assessment and staff recruitment would have a suitable and parsimonious tool to identify Machiavellian traits. During selection interviews, Machiavellians often appear as attractive people to occupy positions of managerial importance because of their great capacity for persuasion, negotiation, emotional control and assertiveness. For the professionals in charge of coaching and the development of people who could hold leadership roles within the working group, the use of the validated scale would allow the professional to take preventive measures. That is, before focusing their efforts on the development of driving skills, professionals could anticipate the negative impact of the leader's behaviours motivated by the darkest facets of his/her personality.

\section{Contributors}

Both authors made substantial contributions in all stages of the article, namely: conception and design, analysis and interpretation of data, discussion, review and approval of the final version.

\section{References}

Ato, M., López, J., \& Benavente, A. (2013). Un sistema de clasificación de los diseños de investigación en psicología. Anales de Psicología, 29(3), 1038-1059. http://dx.doi.org/10.6018/analesps.29.3.178511

Baglin, J. (2014). Improving your exploratory factor analysis for ordinal data: A demonstration using FACTOR. Practical Assessment, Research and Evaluation, 19(5), 2-15. Retrieved March 21, 2015, from http://pareonline.net/getvn.asp?v=19\&n=5 
Bentler, P. (2006). EQS 6 structural equations program manual. Los Angeles: Multivariate Software.

Christie, R., \& Geis, F. L. (1970). Studies in machiavellianism. New York: Academic Press.

Furnham, A., Richards, S. C., \& Paulhus, D. L. (2013). The dark triad of personality: A 10 year review. Social and Personality Psychology Compass, 7(3), 199-216. Retrieved September 12, 2014, from http://www2. psych.ubc.ca/ dpaulhus/research/DARK_TRIAD/ ARTICLES/SPC\%202013.Furnham-Richards-Paulhus. pdf

Gadermann, A. M., Guhn, M., \& Zumbo, D. (2012). Estimating ordinal reliability for Likert-tipe and ordinal item response data. Practical Assessment, Research and Evaluation, 17(3), 1-13. Retrieved February 9, 2013 from http://pareonline.net/pdf/v17n3.pdf

Hair, J. E., Black, W. C., Babin, B. J., Anderson, R. E., \& Tatham R. L. (2010). Multivariate data analysis (6th ed.). Upper Saddle River: Pearson-Prentice Hall.

Hare, R. D. (1985). Comparison of procedures for the assessment of psychopathy. Journal of Consulting and Clinical Psychology, 53(1), 7-16. http://dx.doi. org/10.1037/0022-006x.53.1.7

Hudek-Knežević, J., Kardum, I., \& Mehić, N. (2016). Dark triad traits and health outcomes: An exploratory study. Psychological Topics 25(1), 129-156. Retrieved June 16, 2016, from https://www.researchgate. net/publication/301619172_Dark_triad_traits_and_ health_outcomes_An_exploratory_study

Jones, D. N., \& Figueredo, A. J. (2013). The core of darkness: Uncovering the heart of the Dark Triad. European Journal of Personality, 27(6), 521-531. http://dx.doi.org/10.1002/per.1893

Jones, D. N., \& Paulhus, D. L. (2014). Introducing the Short Dark Triad (SD3): A brief measure of Dark Personality traits. Assessment, 21(1), 28-41. http://dx. doi.org/10.1177/1073191113514105

Linstead, S., Maréchal, M., \& Griffin, R. W. (2014). Theorizing and researching the dark side of organization. Organization Studies, 35(2), 165-188. http://dx.doi. org/10.1177/0170840613515402

Lloret-Segura, S., Ferreres, A., Hernández, A., \& Tomás, I. (2014). El análisis factorial exploratorio de los ítems: una guía práctica, revisada y actualizada. Anales de Psicología, 30(3), 1151-1169. http://dx.doi. org/10.6018/analesp s.30.3.199361

Maples, J. L., Lamkin, J., \& Miller, J. D. (2014). A test of two brief measures of the dark triad: The Dirty Dozen and Short Dark Triad. Psychological Assessment, 26(1), 326-331. http://dx.doi.org/10.1037/a0035084

Marcus, D. K., \& Zeigler-Hill, V. (2016). Understanding the dark side of personality: Reflections and future directions. In V. Zeigler-Hill, \& D. K. Marcus (Eds.), The dark side of personality: Science and practice in social, personality, and clinical psychology (pp.363-374). American Psychological Association.

Muñiz, J., Elosua, P., \& Hambleton, R. K. (2013). Directrices para la traducción y adaptación de los tests: segunda edición. Psicothema, 25(2), 151-157. http:// dx.doi.org/10.7334/psicothema2013.24

Palaiou, A., Zarola, P., \& Furnham, A. (2016). The dark side of personality predicts positive and negative work attitudes. Personality and Individual Differences, 88, 12-16. http://dx. doi.org/10.1016/j.paid.2015.08.029

Paulhus, D. L. (2014). Toward a taxonomy of dark personalities. Current Directions in Psychological Science, 23(6), 421-426. http://dx.doi.org/10.1177/0 963721414547737

Raskin, R., \& Hall, C. S. (1979). A narcissistic personality inventory. Psychological Reports, 45(2), 590-605 http://dx.doi.org/10.2466/pr0.1979.45.2.590

Ronchetti, R., Gauer, G., Vasconcellos, S., Silva, L., Luhring, G., \& Rubin, A. (2014). Psychopathic traits in adolescence: A review. Estudos de Psicologia (Campinas), 31(2), 237-246. http://dx.doi.org/10.15 90/0103-166X201400020 0009

Satorra, A. (2002). Asymptotic robustness in multiple group linear-latent variable models. Econometric Theory, 18, 297-312. http://dx.doi.org/10.1017.S026 6466602182041

Southard, A. C., Noser, A. E., Pollock, N. C., Mercer, S. H., \& Zeigler-Hill, V. (2015). The interpersonal nature of dark personality features. Journal of Social and Clinical Psychology, 34(7), 555-586. http://dx.doi.org/10.1521/ jscp.2015.34.7.555

Spain, S. M., Harms, P., \& Lebreton, J. M. (2013). The dark side of personality at work. Journal of Organizational Behavior, 35(2), 41-60. http://dx.doi.org/10.1002/ job.1894

Stead, R., \& Fekken, G. C. (2014). Agreeableness at the core of the dark triad of personality. Individual Differences Research, 12(4), 131-141. Retrieved August 20, 2015, from http://eds.b.ebscohost.com/ eds/pdfviewer/pdfviewer?sid=939a4617-80da-49d8ab97-541 ce9522e0c\%40sessionmgr102\&vid=0\&h $\mathrm{id}=113$

Zinbarg, R. E., Yovel, I., Revelle, W., \& McDonald, R. P. (2006). Estimating generalizability to a latent variable common to all of a scale's indicators: Acomparison of estimators for omega hierarchical. Applied Psychological Measurement, 30(2), 121-144. http:// dx.doi.org/10.1177/0146621605278814

Received: September 15, 2016 Approved: February 23, 2017 